\title{
Componentes Cognitivos y Afectivos de la Identidad Étnica en Jóvenes Mapuche del Gran Concepción, Chile
}

\section{Cognitive and Affective Components of Ethnic Identity in Mapuche Youths of the Metropolitan Area of Concepción, Chile}

\author{
Natalia Zañartu Canihuante ${ }^{1}$, Claudio Bustos Navarrete ${ }^{2}$, \\ Pamela Grandón Fernández ${ }^{3}$ y Andrea Aravena Reyes ${ }^{4}$ \\ ${ }^{1}$ Facultad de Psicología, Universidad San Sebastián Sede Concepción \\ 2 Departamento de Psiquiatría y Salud Mental, Facultad de Medicina, Universidad de Concepción \\ ${ }^{3}$ Departamento de Psicología, Facultad de Ciencias Sociales, Universidad de Concepción \\ ${ }^{4}$ Departamento de Antropología, Facultad de Ciencias Sociales, Universidad de Concepción
}

\begin{abstract}
Este artículo aborda el proceso de identificación étnica en 15 estudiantes mapuche de educación superior de 5 casas de estudios del Gran Concepción, Chile. Los jóvenes, entre 18 y 24 años, fueron 10 mujeres y 5 hombres. Es un estudio cualitativo retrospectivo, con un diseño interpretativo fenomenológico y un muestreo teórico, no probabilístico intencionado (bola de nieve). Se realizaron entrevistas individuales en profundidad, las que fueron analizadas según una malla temática de 5 categorías. Se describen los componentes cognitivos y afectivos de la identidad mapuche. La identidad étnica estaría fuertemente vinculada al proceso de escolarización de las personas. Se observan 3 despertares culturales durante este proceso: al inicio de la escolarización en la segunda infancia, al comienzo de la educación secundaria e inicio de la adolescencia y, finalmente, al ingreso a la educación superior, que coincide con el término de la adolescencia y comienzo de la adultez joven. La identidad étnica se caracteriza por ser dinámica, es decir, se modifica y transforma permanentemente, a través de un proceso de aprendizaje autorregulado, que presenta características individuales y colectivas y que surge como respuesta a las constantes tensiones identitarias que viven los y las jóvenes. La vivencia del cuestionamiento permanente de la identidad en los jóvenes es asociada a sentimientos de malestar. No obstante, existen también sentimientos de bienestar, felicidad y orgullo en el desarrollo de la identidad étnica. Ambos sentimientos impactan la salud mental de las personas.
\end{abstract}

Palabras clave: identidad étnica, identidad mapuche, bienestar, tensiones identitarias

This article addresses the ethnic identity formation process of 15 students of Mapuche ethnicity attending 5 higher education centers in the Metropolitan area of Concepción, Chile. The subjects were 10 young women and 5 young men whose ages ranged from 18 to 24 years. This is a retrospective qualitative study with a phenomenological interpretative design and theoretical, non-probability purposive (snowball) sampling. Individual in-depth interviews were conducted and analyzed based on a 5-category thematic grid. A description is presented of the cognitive and affective components of Mapuche identity. Ethnic identity appears to be strongly linked to each individual's schooling process. Three moments of cultural awakening are observed during this process: when schooling begins in second infancy, upon entering adolescence and starting secondary school, and, finally, at the start of higher education, which coincides with the end of adolescence and the entry into young adulthood. Ethnic identity is dynamic; i.e., it is continually modified and transformed through a process of self-regulated learning that has individual and collective characteristics and which arises in response to the constant identity-related pressures experienced by young people. Repeatedly experiencing that their identity is challenged is associated with feelings of unease among young people. However, the development of an ethnic identity is also linked to feelings of well-being, joy, and pride. Both affective polarities have an impact on people's mental health.

Keywords: ethnic identity, Mapuche identity, well-being, identity-related tensions

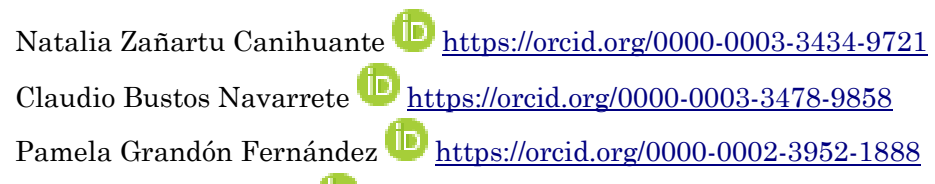

Andrea Aravena Reyes (iD) http://orcid.org/0000-0001-7112-3794

El artículo es parte de la tesis de la autora principal para optar al grado de doctor en psicología por la Universidad de Concepción, dirigida por la profesora Andrea Aravena Reyes Fue financiado por la Beca Doctorado Nacional CONICYT No 21141182 y patrocinado por el proyecto FONDECYT N 11130384 , titulado "Imaginarios sociales de la identidad mapuche en el Gran Concepción", de la Dra. Andrea Aravena Reyes, quien es, además, coautora de esta publicación.

La correspondencia relativa a este artículo debe ser dirigida a Natalia Zañartu Canihuante, Facultad de Psicología, Universidad San Sebastián, Lientur 1457, Concepción, Región del Biobío, Chile. Email: natalia.zanartuc@docente.uss.cl 
En Chile la población mapuche constituye el pueblo originario más grande del país. El 13\% de la población, equivalente a 2.185 .792 personas, se declaró parte de alguno de los nueve pueblos originarios que el Estado reconocía cuando se realizó el último censo en el año 2017: Aymara, Quechua, Rapanui, Atacameño, Coya, Diaguita, Mapuche, Kawésqar y Yagán, a los que en el futuro se debe agregar el pueblo Chango. El Instituto Nacional de Estadísticas (2018) ha descrito un aumento en la población que forma parte de los pueblos originarios desde 2002 a 2017. De esta cifra, 1.745.147, es decir, el 9,9\% de las personas censadas se reconoce como parte del pueblo Mapuche. Las zonas con mayor presencia de población mapuche son urbanas y se encuentran en las regiones Metropolitana, de La Araucanía, Los Lagos y Biobío, es decir, en la zona centro sur del país.

La relación entre el pueblo Mapuche y el Estado chileno ha sido históricamente conflictiva. La demanda de la devolución del territorio ancestral de parte del pueblo Mapuche se ha transformado en una de las principales aristas del llamado "conflicto mapuche". No obstante, la tensión que existe entre ambos trasciende a la demanda territorial y da cuenta de la falta de estrategias efectivas del Estado de Chile para afrontar la situación, lo que lo mantiene enfrentado al pueblo originario más numeroso hasta hoy en día, en pleno siglo XXI (Cayuqueo, 2012; Merino et al., 2017).

Las investigaciones realizadas durante el siglo XX y comienzos del XXI (Aravena \& Baeza, 2017; Zañartu Canihuante et al., 2017) respaldan la idea de que la tensión entre el pueblo Mapuche y el Estado ha sido traspasada a una parte de la sociedad chilena no mapuche, quienes portarían estigmas y prejuicios en torno a la población mapuche, perpetuando la imagen de un sujeto inferior, víctima de procesos de humillación, subestimación y franca discriminación. Esto, sin duda, permea fuertemente el desarrollo de la identidad en personas mapuche, sobre todo en los y las jóvenes, pues la construcción de la identidad es un proceso que se ha definido históricamente desde la psicología en relación con el medio y la cultura en la que el sujeto habita (Erikson, 1968/1971; Vygotski, ca. 1928-1931/1996).

Nuestra investigación estuvo orientada a conocer los componentes cognitivos y afectivos de la identidad mapuche urbana en jóvenes estudiantes de educación superior de la ciudad de Concepción, Región del Biobío.

\section{Antecedentes Teóricos}

El constructo de identidad ha sido estudiado en psicología principalmente desde la psicología social y del desarrollo. Específicamente, destacan los aportes de la teoría de la identidad social, la teoría del desarrollo psicosocial y la teoría del desarrollo sociocultural (Erikson, 1968/1971; Tajfel, 1981/1984; Vygotski, ca. 19281931/1996). Todas estas teorías plantean desde sus orígenes que el contexto social es fundamental en los procesos de desarrollo humano y la formación de la identidad. No obstante, el desarrollo posterior de estas teorías siguió una línea más cognitiva, distanciándose de los componentes afectivos y socioculturales de la identidad que estas teorías buscaban esclarecer (Peris Pichastor \& Agut Nieto, 2007).

Desde la psicología social, destaca la teoría de la identidad social de Henri Tajfel (1981/1984). Esta teoría define la identidad social como "la parte del autoconcepto del individuo que deriva del conocimiento de su pertenencia a un grupo social (o grupos sociales) junto con el significado emocional y valorativo asociados a dicha pertenencia" (Tajfel, 1981/1984, p. 292). La identidad social se construye a partir de los procesos de categorización, comparación y competición social. Mientras la categorización social destaca las diferencias con el exogrupo y las semejanzas con el endogrupo, la comparación social entrega una valoración de esta pertenencia, que puede ser positiva o negativa, dependiendo de cuan favorable sea formar parte del grupo o no. Se trata, entonces, no solo de ser diferente, sino también de ser mejor. La competencia por una identidad social positiva tiene como objetivo final maximizar la autoestima de las personas.

La identidad étnica forma parte de la identidad social, correspondiendo a la parte del autoconcepto que se deriva de la pertenencia a un grupo étnico. Se constituye por dos procesos principales: la exploración o búsqueda de información y la afirmación étnica (Phinney \& Ong, 2007). La exploración, por una parte, se asocia con procesos de aprendizaje, como resultado de la búsqueda de información y de las vivencias asociadas a la propia cultura. Por otra, la afirmación se refiere a la vinculación afectiva, caracterizada por sentimientos y emociones que surgen hacia el grupo de pertenencia.

Para Phinney (1990), el componente afectivo de la identidad étnica se conforma no solo desde los sentimientos de pertenencia, sino también por sentimientos de orgullo, que son compartidos por las personas que forman parte del grupo étnico. Los sentimientos positivos asociados a la identidad étnica son importantes, porque, además de generar la percepción de bienestar, podrían actuar como factor protector contra prácticas 
sociales, como la discriminación (Genna \& Espinosa, 2012). El bienestar subjetivo es entendido como la percepción relativamente continua que tiene un sujeto de que su vida es agradable y positiva; se compone de tres aspectos, dos valorativos, afecto positivo y negativo, y el último, de carácter más cognitivo, la satisfacción con la vida. Las investigaciones confirman que la identidad étnica se correlaciona directamente con las mediciones de bienestar subjetivo, como la autoestima (Diener, 2000; Espinosa Pezzia \& Tapia, 2011; Pavot \& Diener, 2008).

Durante la juventud, el proceso de exploración de la identidad étnica es importante, porque la conformación de la identidad cobra fuerza a través de los distintos conflictos y tensiones que aparecen en la diferenciación que hace el joven de sí mismo (Jiménez Bustos et al., 2017). La adolescencia como etapa del desarrollo tiene como tarea principal resolver la crisis de la identidad que busca integrar varias visiones de sí mismo en el autoconcepto, consolidando, además, la autoestima de las personas (Erikson, 1968/1971). Este es un momento crítico que tensiona los aprendizajes internalizados en la socialización primaria, que está a cargo generalmente de la familia.

Los estudios que existen en Chile de autodefinición étnica en jóvenes mapuche destacan aspectos objetivos y subjetivos que formarían parte de los componentes cognitivos y afectivos de la identidad mapuche. El principal indicador objetivo de la identidad mapuche es la filiación, entendida desde el vínculo consanguíneo o küpal, que se traspasa a través de la sangre o el apellido, y el territorio de procedencia o tuwün. El küpal y el tuwün generalmente están vinculados y se refieren a los vínculos familiares y territoriales de origen. El aspecto físico o rasgos fenotípicos que son asociados al pueblo Mapuche son mencionados también por los jóvenes cuando hablan de su identidad étnica; además, consideran la condición de hablante o no de mapudungun o lengua mapuche. Finalmente, la participación en ritos o ceremonias evidencia el vínculo comunitario que se tiene, tanto con la familia como con la comunidad (Merino \& Tocornal, 2012).

Para las personas jóvenes mapuche los aspectos subjetivos que se refieren a la identidad indígena tienen relación con sentirse mapuche, más allá de la presencia de uno o más indicadores objetivos. De esta forma, mientras que ser mapuche puede relacionarse con el apellido, sentirse mapuche involucra un compromiso emocional, interaccional y social, que se describe como una identidad activa y proactiva, más que pasiva o instrumental. Así, mientras las expresiones forman parte del discurso público, los sentimientos formarían parte del discurso privado de la identidad mapuche (Merino \& Tileagă, 2011; Verkuyten \& Wolf, 2002).

En el contexto actual de Chile, los y las jóvenes mapuche ven su identidad étnica constantemente tensionada. En su mayoría habitan en zonas urbanas y no son hablantes de mapudungun (Ministerio de Desarrollo Social, 2015). Por tanto, no forman parte de las categorías a las que ellos mismos asignan más valor a la hora de definir qué es ser o no mapuche. Para Alfaro (2007), los y las jóvenes mapuche estarían en un proceso continuo de aprendizaje de su identidad, en un ejercicio reflexivo permanente acerca de qué lugar ocupan en el Chile de hoy. La pérdida de la identidad y la consecuente interpelación a la misma los mantiene en un proceso de negociación constante, reconociéndose como herederos de una cultura ancestral, pero también de una cultura que históricamente ha sido discriminada y que, consecuentemente, ha perdido mucho de su saber (Oteíza \& Merino, 2012).

Si bien las personas jóvenes son la parte de la población indígena más expuesta a los procesos de aculturación, forman parte de los liderazgos de movimientos de reivindicación cultural en contra de las políticas públicas imperantes (Pérez Ruiz, 2011). En Chile, como en el resto de América Latina, la participación de personas más jóvenes en movilizaciones político-sociales a favor o en contra de los gobiernos imperantes ha generado gran interés por conocer sus demandas, ya que representan a un grupo con influencia en la opinión pública (Alfaro, 2007).

Interesa, por tanto, estudiar la identidad étnica en los y las jóvenes mapuche, incluyendo los componentes afectivos de esta. El estudio de la afectividad asociada a la identidad está muy poco desarrollado en la literatura chilena, siendo su omisión grave por el papel que cumple en el proceso de afirmación cultural e influencia en el desarrollo del autoconcepto y la autoestima. Resulta interesante destacar que los estudios que existen hasta la fecha en nuestro país son cualitativos, han sido realizados principalmente en la región Metropolitana, donde se encuentra Santiago, la capital de Chile, y en La Araucanía, región con mayor población rural mapuche. Están centrados en población adulta, mayoritariamente en mujeres y/u organizaciones, o en alumnos de estudios secundarios (educación media), cuya característica principal es la dependencia habitacional con los padres o, en su defecto, viajes de corto alcance durante el día para trasladarse a sectores semiurbanos a estudiar. Es decir, es población que está por debajo de la mayoría de edad legal, por tanto, no tiene aún estudios superiores y no se ha visto obligada a migrar a otra ciudad, con 
el distanciamiento de su familia y territorio de procedencia que esto exige. El ingreso a la educación superior supone desafíos académicos y cognitivos, pero también de adaptación sociocultural a un contexto que no necesariamente es protector de la identidad social y étnica de las personas o de su bienestar subjetivo y social (Sarmiento et al., 2019).

Nuestro estudio aborda la identidad étnica como un proceso social complejo que se gesta desde la primera infancia en adelante, de manera dinámica y en relación con el entorno sociocultural del individuo. Sin embargo, hace énfasis en las crisis evolutivas que atraviesan las personas jóvenes, ya que estas tendrán consecuencias importantes en la formación de su autoconcepto y, por ende, en la identidad. Buscamos aportar a la comprensión de la conformación de la identidad mapuche, en el contexto actual que está marcado por un clima de violencia y discriminación hacia dicho pueblo. Se sitúa en el Chile urbano de hoy.

\section{Método}

\section{Diseño}

Nuestra investigación tuvo un diseño descriptivo-relacional y fue cualitativa, con un enfoque interpretativo fenomenológico, porque buscamos comprender, desde la perspectiva de los propios sujetos investigados, cuáles son los sentidos y significados con que interpretan aspectos cotidianos de su identidad mapuche. Responde a una mirada epistemológica crítica, en tanto visibiliza el contexto de tensión permanente e incluso de discriminación que vivencia este grupo étnico. No obstante, no desconoce el carácter ecológico que tiene el proceso de identificación cultural, ya que adoptamos una mirada desde la psicología sociocultural, por tanto, reconocemos la participación de otros sujetos y subsistemas sociales en la conformación de la identidad social, étnica y mapuche.

\section{Participantes}

Utilizamos un muestreo teórico, no probabilístico intencionado. La estrategia de búsqueda sucesiva de casos la hicimos por bola de nieve, considerando personas clave o porteros (Pérez-Luco Arenas et al., 2018), tales como dirigentes estudiantiles, que pudieran facilitar el primer acercamiento a la muestra, considerando la confianza que se requiere para hablar de vivencias personales (Krause, 1995).

La población de nuestra investigación correspondió a jóvenes mapuche estudiantes de educación superior, que se encontraban entre los 18 a 24 años y que habitaban en El Gran Concepción, Chile. Los jóvenes debían cumplir con los siguientes criterios de inclusión: (a) definirse como mapuche, (b) contar con al menos un apellido mapuche o el certificado de calidad indígena de la Corporación Nacional de Desarrollo Indígena y (c) tener la condición de alumno regular de una universidad o instituto técnico. Excluimos a cualquier persona que, aun teniendo apellidos mapuche, considerara que no pertenecía a este pueblo originario. Todas las personas fueron contactadas telefónica y personalmente por una antropóloga investigadora hablante de mapudungun. Cuatro sujetos declinaron participar por mostrar conflictos de interés entre su identidad activista y la participación en investigaciones para universidades chilenas.

Participaron 15 personas, 10 mujeres y 5 hombres, con edades entre los 19 y los 24 años, todos estudiantes de educación superior técnica o universitaria. Las instituciones educacionales donde pertenecían los participantes fueron la Universidad de Concepción, la Universidad del Biobío, el Instituto Profesional INACAP (Instituto Nacional de Capacitación Profesional) y el DUOC (Departamento Universitario Obrero y Campesino).

\section{Instrumento}

Obtuvimos la información mediante la técnica de entrevista individual en profundidad, basada en un guion semiestructurado que establecimos a partir de la revisión de la literatura y la experiencia de la investigadora principal, pero que, a la vez, permitiera al entrevistado/a hablar con libertad, fluidez y tranquilidad acerca de las vivencias que asocia al proceso de conformación de su identidad mapuche (Canales Cerón, 2006). Las entrevistas tuvieron un promedio de duración de 45 minutos aproximadamente, con un tiempo mínimo de 38 y un máximo de 52 minutos. La pauta de preguntas se encuentra en el Anexo. 


\section{Procedimiento}

A todos los participantes se les aplicó un protocolo de consentimiento informado, de acuerdo con los requisitos que establece el Comité Nacional de Ciencia y Tecnología de Chile. Se garantizó la confidencialidad de todos los datos personales en todo momento de la investigación. La entrevista fue realizada por una investigadora hablante de mapudungun y altamente calificada en investigación. Se solicitó información a la Dirección de Servicios Estudiantiles de la Universidad de Concepción para ser entregada a las personas que participaron de la investigación, en el caso de que requirieran apoyo psicológico.

Se contactó personalmente o por teléfono a cada estudiante para extender la invitación a participar de la investigación. Se establecieron distintos lugares para realizar la entrevista según fuera la preferencia de cada participante. Así, se fijó una fecha y lugar de común acuerdo para realizar la entrevista. El lugar varió entre la universidad y sus cercanías, la oficina de la entrevistadora y la casa del entrevistado. Todas las entrevistas se iniciaron con el procedimiento de consentimiento informado y la firma de la respectiva acta, con la entrega de una copia a la persona entrevistada. Los datos fueron transcritos literalmente, a partir de la grabación en audio digital, registrando las expresiones verbales, tanto formales como informales.

\section{Análisis de Datos}

Basamos el análisis de los datos en la metodología de malla temática, ya que permite combinar de manera fluida la información teórica y disponible previa, característica de un enfoque hipotético, con la emergencia de categorías a partir de los datos, propio de un enfoque inductivo. La malla temática es un instrumento de análisis que se genera a partir de las hipótesis de investigación preexistentes y/o de los grandes temas explorados a través de la pauta semiestructurada de entrevista. Sirve para realizar la "captura" de significados entregados a través del discurso de los participantes, estableciendo un vínculo más directo con el objeto de estudio. Una vez establecida la malla temática inicial, comienza la codificación en vivo a partir de los textos de las entrevistas, para realizar adecuaciones que llevan a la malla temática final (Baeza, 2002).

Las cinco categorías principales de la malla temática fueron planteadas a priori, basándonos en la literatura y la experticia de la investigadora principal. Luego, para garantizar la triangulación analítica, dos investigadoras realizaron la codificación inductiva de manera independiente, entrevista por entrevista, creando subtemas, de acuerdo con los discursos de los participantes. Esto se realizó hasta alcanzar el punto de saturación de contenidos. Finalizado este proceso, se realizaron las modificaciones requeridas por acuerdo de ambas, hasta lograr confeccionar la versión definitiva del árbol de categorías y subcategorías. El proceso final de comparación de las categorías generadas con los discursos de los participantes se realizó por parte de la investigadora principal, para evitar omisiones y duplicaciones. Utilizamos el software de análisis cualitativo NVivo v. 11 (QSR International, 2015).

\section{Resultados}

Presentamos los resultados organizados de acuerdo con las cinco categorías principales de la malla temática. La primera categoría, relacionada a la identidad étnica, es la autoadscripción o significado de ser mapuche. En segundo lugar, está la idea de que la identidad étnica es dinámica, ya que permanece en movimiento a través del desarrollo humano. En tercer lugar, la identidad se expresa, según sea esta activa o pasiva. En cuarto lugar, la identidad se asocia a sentimientos de bienestar y/o malestar y, en quinto lugar, esta se refleja en valores compartidos que llevan a prácticas culturales cotidianas. En la Tabla 1 presentamos las categorías principales, junto a los subtemas derivados inductivamente a partir de los datos.

Al hablar acerca del significado de ser mapuche, nuestros entrevistados y entrevistadas describen su autodescripción, concretamente en dos líneas: küpal y tuwün. La filiación es descrita a través de la sangre, familia o apellido y el territorio con su historia, que es compartida por todos quienes habitan esta comunidad.

Mari mari [un saludo; se ríe, demuestra un poco de nerviosismo], inche pingen tati [yo me llamo; menciona su nombre], inche chillkatulen [yo estudio; menciona la carrera] en [menciona especialidad y universidad]. Mew, kafey inche kuzawkulen, inche mulen Puente Alto [trabajo en el comercio ambulante, también hago malabares un poquito, crecí y me crie en Puente Alto hasta los 18 años], warria mew, welü folil kupan Lumako mew [provengo/mis raíces/orígenes son o están en Lumaco] y eso, tengo [años], soy estudiante, cuando decidí venirme a estudiar a Conce [Concepción]. (Persona 15, mujer) 
Podemos observar cómo en su presentación la participante, además de decir su nombre, realiza una breve biografía que comprende tanto lugares como actividades relevantes.

Tabla 1

Temas y Subtemas de la Malla Temática

\begin{tabular}{|c|c|c|c|}
\hline \# & Categoría y subcategoría & Descripción & Casos \\
\hline 1. & Autoadscripción & Características que definen la identidad del pueblo mapuche como tal. & \\
\hline 1.1. & Aprendizaje permanente & $\begin{array}{l}\text { Ser mapuche implica aprender constantemente elementos culturales } \\
\text { relevantes. }\end{array}$ & 11 \\
\hline 1.2 . & Filiación & Ser mapuche se asocia a lazos sanguíneos (küpal) y de territorio (tuwün). & \\
\hline 1.2.1. & Por sangre o apellido (küpal) & $\begin{array}{l}\text { Autoadscripción a partir del vínculo sanguíneo que se traspasa, como ente } \\
\text { vivo, que transfiere cultura. }\end{array}$ & 13 \\
\hline 1.2 .2$. & Por territorio e historia (tuwün) & $\begin{array}{l}\text { Asociación de la identidad étnica al territorio, como ente vivo que agrupa } \\
\text { relaciones entre familias y comunidades. Aquí se incluyen contenidos que } \\
\text { están asociados a la historia de los territorios y familias que ahí habitan. }\end{array}$ & 12 \\
\hline 1.3. & Tensiones identitarias & $\begin{array}{l}\text { Ser mapuche urbano implica una tensión permanente entre la } \\
\text { autoadscripción y la interpelación del endogrupo y del exogrupo por la } \\
\text { posesión (o no) de los elementos culturales propios de lo mapuche. }\end{array}$ & 6 \\
\hline 2. & Dinámica & Alude a los cambios que sufre la identidad a lo largo del ciclo vital. & \\
\hline 2.1. & Despertar cultural & $\begin{array}{l}\text { Consciencia de pertenencia, producto de hitos vitales, que gatillan procesos } \\
\text { de búsqueda, y exploración, que explican la conformación de la identidad en } \\
\text { los jóvenes mapuche. }\end{array}$ & 9 \\
\hline 2.2 . & Educación primaria & $\begin{array}{l}\text { Cambios identitarios que se registran en los primeros años de escolarización. } \\
\text { Coincide con la segunda infancia. }\end{array}$ & 13 \\
\hline 2.3 . & Educación secundaria & $\begin{array}{l}\text { Cambios identitarios asociados a la segunda etapa de la escolarización. } \\
\text { Coincide con la adolescencia. }\end{array}$ & 11 \\
\hline 2.4 . & Educación superior & $\begin{array}{l}\text { Cambios identitarios asociados a la última etapa de la formación } \\
\text { educacional del sujeto. }\end{array}$ & 9 \\
\hline 3. & Expresión de la identidad & $\begin{array}{l}\text { La identidad mapuche se expresa de distintas maneras, tanto de forma } \\
\text { activa como pasiva. }\end{array}$ & \\
\hline 3.1. & Activa o reivindicativa & $\begin{array}{l}\text { Es el tipo de identidad que agrupa las acciones, tanto individuales como } \\
\text { colectivas, orientadas a la reafirmación cultural. Recibe una valoración } \\
\text { mayor. }\end{array}$ & \\
\hline 3.1.1. & Adoptar postura activa & $\begin{array}{l}\text { La identidad implica tomar partido, adoptar una actitud positiva hacia las } \\
\text { conductas de búsqueda, exploración y aprendizaje. }\end{array}$ & 10 \\
\hline 3.1.2. & $\begin{array}{l}\text { Responsabilidad moral } \\
\text { individual }\end{array}$ & $\begin{array}{l}\text { Sentimiento ético y de obligación moral que lleva a la persona a sentir la } \\
\text { necesidad de actualizar su self en sintonía con la cultura mapuche. }\end{array}$ & 9 \\
\hline 3.1.3. & Retribución & Acciones de restitución hacia la comunidad o el grupo de pertenencia. & \\
\hline 3.1.3.1. & Técnica/profesional & $\begin{array}{l}\text { Se centra en la idea de servir técnicamente a su cultura, a través del } \\
\text { ejercicio de la profesión, en apoyo al pueblo Mapuche. }\end{array}$ & 10 \\
\hline 3.1.3.2. & Traspaso cultural & $\begin{array}{l}\text { Acciones que apuntan a transmitir conocimientos propios de la cultura y, } \\
\text { sobre todo, su lengua. }\end{array}$ & 10 \\
\hline 3.2 . & Instrumental o pasiva & $\begin{array}{l}\text { Adscripción a la identidad sin involucramiento cultural y de manera } \\
\text { estratégica para acceder a beneficios estatales como, por ejemplo, becas para } \\
\text { educación. Recibe una valoración menor, porque no obedece a procesos de } \\
\text { reivindicación cultural. }\end{array}$ & 4 \\
\hline 4. & Sentimientos & Sentimientos que se desprenden de la identidad étnica. & \\
\hline 4.1 . & Bienestar & $\begin{array}{l}\text { Sentimientos positivos producto de la identidad étnica mapuche que generan } \\
\text { bienestar. }\end{array}$ & \\
\hline 4.1.1. & De orgullo y felicidad & $\begin{array}{l}\text { Sensación de orgullo/honor de ser parte de lo mapuche, asociada usualmente } \\
\text { a la historia de lucha. }\end{array}$ & 14 \\
\hline 4.1.2. & De pertenencia & $\begin{array}{l}\text { Sentimiento de ser parte de algo más grande que la propia individualidad, } \\
\text { algo colectivo con lo que comparten valores. }\end{array}$ & 12 \\
\hline 4.1.3. & De trascendencia & $\begin{array}{l}\text { Sentimientos de fuerza espiritual (newen) asociados a los aspectos } \\
\text { espirituales de la cosmovisión mapuche. }\end{array}$ & 6 \\
\hline 4.2 . & De malestar & $\begin{array}{l}\text { Sentimientos negativos que son asociados al proceso de desarrollo de la } \\
\text { identidad étnica. Principalmente, se refieren a incomodidad producto de la } \\
\text { tensión identitaria. }\end{array}$ & 9 \\
\hline
\end{tabular}




\section{Tabla 1 (Conclusión)}

\section{Temas y Subtemas de la Malla Temática}

\begin{tabular}{|c|c|c|c|}
\hline$\#$ & Categoría y subcategoría & Descripción & Casos \\
\hline 5. & Valores compartidos & $\begin{array}{l}\text { Participación en prácticas, tanto tradicionales como no tradicionales, que } \\
\text { reflejan valores compartidos con el pueblo Mapuche. }\end{array}$ & \\
\hline 5.1 . & Prácticas culturales cotidianas & $\begin{array}{l}\text { Rutinas que los entrevistados consideren propias de la cultura mapuche y } \\
\text { que son aplicables a su vida cotidiana. }\end{array}$ & \\
\hline 5.1 .1 & $\begin{array}{l}\text { Importancia de la familia y los } \\
\text { antiguos }\end{array}$ & $\begin{array}{l}\text { Importancia asignada a las personas mayores, incluyendo antepasados vivos } \\
\text { y muertos. }\end{array}$ & 11 \\
\hline 5.1 .2 & Colectividad & $\begin{array}{l}\text { Importancia dada a lo colectivo y al cuidado del otro. Se refleja en la } \\
\text { participación en distintas agrupaciones que son entendidas como } \\
\text { comunidades urbanas. También existe una orientación hacia la formación de } \\
\text { grupos estrechos de apoyo, basados en la familia o la amistad. }\end{array}$ & 14 \\
\hline 5.2 . & Elementos tradicionales & $\begin{array}{l}\text { Ritos y ceremonias que están ligadas de manera ancestral a la cultura. } \\
\text { Ejemplos de estos son juegos, como el palín, rogativas, rutinas de } \\
\text { distribución y orientación de los muebles en la casa. }\end{array}$ & 14 \\
\hline 5.3. & Lengua & Énfasis en el rescate, aprendizaje y socialización del mapudungun. & 12 \\
\hline 5.4 . & Naturaleza & $\begin{array}{l}\text { Relación de respeto y cuidado del entorno en el que habitan, fundada en la } \\
\text { cosmovisión mapuche. }\end{array}$ & 9 \\
\hline
\end{tabular}

Nota. Subtemas sin casos corresponden a categorías de agrupación utilizadas para ordenar categorías en las cuales se realizan codificaciones específicas.

Las tensiones identitarias hablan acerca de momentos de profundos cuestionamientos en torno a la identidad indígena. Este proceso se describe como confuso, permanente y acompañado de sentimientos de incomodidad y malestar:

Sí, pu, igual hubo un momento, porque igual yo soy, dicen allá, chicha con agua [ni una cosa ni otra], allá yo estudié en un colegio con puros cabros mapuche y allá a los no mapuche eran como a los que leseaban más, pero uno va aprendiendo el sentido de que al final lo mapuche, y eso es cierto, cuando ya me puse viejo, ya, leí más sobre el tema que tal vez la sangre tira, pero no tira tanto, no tira tanto como en donde uno se crio, porque yo me acuerdo cuando fui a, estudié en [nombra colegio], un colegio por allá por allá por la montaña, me decía champurria [alude a la condición de mestizo], chicha con agua y toda la cuestión, pero yo, después con esos cabros se ve toda la vida, porque son sus amigos de infancia y uno lesea y de repente sale a carretear [salir a divertirse] y todo eso, pero es como parte de la vida no más y uno va aprendiendo de eso, como que echa después, uno en ese tiempo como era chico, como que igual, no sé pu, no estaba confundido, pero como que decía que soy, como al final soy wingka [persona de raza blanca] o soy mapuche, pero uno después dice "na pu, soy lo que soy no más" y al final lo que importa es la historia de cómo, la historia de vida de uno (...) (Persona 9, hombre)

Esta tensión constante sobre la identidad se asocia a un aprendizaje permanente de la identidad, que se genera de manera consciente y autorregulada, como una estrategia de afrontamiento ante el conflicto cognitivo-afectivo que surge. Se percibe como una responsabilidad o deber y se relaciona con el aprendizaje de la cosmovisión mapuche en general. Este proceso es tanto individual como colectivo:

Después, cuando entré a la universidad, me tocó conocer, o sea, conocí gente que estaba, ya, como buscando la forma de revitalizar todo esto y ahí como que no dije "ah, ya no quiero... quiero volver a aprender, quiero hacer algo" y ahí empecé a trabajar con un grupo de chicos acá, intentamos formar un grupo para hacer un taller de mapudungun que, al final, no resultó, pero el grupo sí se logró formar y se ha ido trabajando, ahora, por tiempo, no puedo trabajar mucho con ellos, po, y también quise... hice el intento de integrarme a una comunidad acá (...) (Persona 1, mujer)

Si bien la identidad presenta aspectos estables, se muestra dinámica a lo largo de la vida de las personas. Los aspectos constantes que relatan los sujetos mostrarían que las personas siempre tienen consciencia de su identidad; sin embargo, en determinados momentos de su vida, esta se visibiliza, tensiona, conflictúa, modifica o reafirma:

O sea, yo creo que pueden ser los primeros años, tal vez, en básica, donde uno tuvo que compartir por primera vez con gente que era, era como distinta a uno, en sentido que uno, no conociendo distintas realidades dentro de lo que es la inocencia de uno, también a uno lo trataban distinto. No sé, a ver que puede ser, de repente el mismo color de piel o el apellido que a uno lo molestaban o si no, tantas cosas en realidad. (Persona 9, hombre)

Soy mapuche, pero sí, ha sido a medida que han ido pasando los años, una búsqueda y una necesidad el reencontrarme con mis orígenes como más directamente. (Persona 1, mujer) 
Existen hitos que marcan la toma de consciencia de pertenencia a un determinado grupo cultural. Esta experiencia se vive como un despertar cultural, que adquiere diversas formas a lo largo del proceso evolutivo. El primer despertar cultural coincide con el inicio de la segunda infancia, asociado al ingreso a la escolarización. En este, el niño o niña se da cuenta de que pertenece a un grupo distinto al dominante, ligado a características negativas. Un segundo despertar cultural se produce en la adolescencia, vinculado al ingreso a la educación media y superior. Este segundo despertar se asocia a la confirmación de la pertenencia al pueblo Mapuche, ahora de forma positiva, usualmente emparejada a acciones de reivindicación y retribución:

Cuando entré a la universidad el 2014 recién empecé a darme cuenta, como a tomar consciencia de que tenía que hacer algo por recuperar lo que era mío, como la identidad mapuche, igual estaba súper perdida, como una crisis de identidad y todo al venirme para acá. (Persona 10, mujer)

La toma de consciencia de pertenencia a un grupo distinto al dominante, el que no es valorado socialmente por los chilenos no mapuche y, sobre todo, por los libros de historia utilizados para enseñar en la escuela, desencadena, en primera instancia, sentimientos de malestar, principalmente de incomodidad, que impulsan a la persona hacia un proceso de búsqueda y exploración de sus orígenes:

Por ejemplo, yo estaba en la básica y empezamos a hablar de la conquista de Chile y, de repente, hablaban de que estaban los gobernadores aquí con su gente parando ciudades, pero no podían porque estaban los mapuche, los mapuche eran como los que eran los antagonistas, personajes que los planteaban como personajes que trancaban el progreso de Chile, que eran como antagonistas de la historia y así, yo me sentía y yo era chico, era chico, debía haber tenido tercero o cuarto básico, no me acuerdo, y pensaba ¿qué onda?, mi gente era la mala, era la antagonista, era la que evitaba que Chile progresara. Esos eran los primeros cuestionamientos sobre la identidad chilena, o sea, chilena mapuche, sobre ¿qué soy?, ¿qué hago? (Persona 6, hombre)

Este proceso se inicia involucrando a personas cercanas, generalmente a la familia, en diálogos, encuentros y conversaciones que giran alrededor de temáticas relacionadas con el origen de la persona. Luego, la búsqueda se abre a la comunidad o alguna agrupación de la cual se forme parte:

Bueno, ahí eso fue este año, sí, el verano del 2017 y, bueno, todo ese proceso, yo como más despierta, preguntándole a mi abuelo hartas cosas como de su vida de antes, como de su vida mapuche, porque su abuelo, o sea, su mamá le hablaba harto, era hablante y como que practicaba y todo y como buscando, no sé, preguntándole palabras como en chedungun [otra forma de referirse al mapudungún], enseñándome, iah! (Persona 10, mujer)

No, no, no siempre yo me he sentido mapuche, porque como yo nací en Chiguayante, estudié en un colegio en Chiguayante y todos los niños del colegio de mi curso personalmente nadie sabía que era un mapuche, si existían, si estaban en el museo, si eran parte de la historia de los libros de clases no más, entonces, yo como... yo crecí en ese ambiente, daba lo mismo la verdad, no me identificaba con mapuche, a pesar que desde chiquitita fui al campo y sabía que mi mamá, que mi abuelita eran mapuche, veía gente que estaba vestida, escuché también varias veces hablar en mapudungun, pero jamás me cuestioné que yo también lo fuera. (Persona 4, mujer)

Las participantes comienzan a buscar información, en un intento por resolver la incomodidad que les genera no saber si ser mapuche es algo que deben considerar bueno o malo:

Después me vine a la ciudad, como en la enseñanza básica, y ahí paso como un tiempo alejada de todo, quizás no me llamaba tanto la atención, sí, siempre quise volver a hablar, siempre tuve la inquietud y les preguntaba a mis tíos cosas y, cada vez que iban a la casa, les decía "¿Tío, le puedo grabar y usted hable mapudungun?" [risas] y mis tíos se reían no más. (Persona 1, mujer)

La autodescripción se acompaña, entonces, de cuatro tipos de sentimientos: de pertenencia, de bienestar (orgullo y felicidad), de malestar y de trascendencia. Los componentes afectivos permanecen tanto como los cognitivos en el curso del desarrollo de la identidad, acentuándose o atenuándose, según sea el contexto del individuo y su etapa de desarrollo humano.

La identidad mapuche se asocia a sentimiento de pertenencia, de ser parte de un grupo mayor con el cual se comparte una historia y valores:

Mapuche ta inche [yo soy mapuche]... bueno, es un trabajo, una experiencia que viene hace poco, mi identidad con el tiempo se ha ido afirmando. Cuando era pequeña no me sentía, no me identificaba como persona mapuche y ahora, con todo el conocimiento que he adquirido día a día, el sentimiento de ser parte de un pueblo. (Persona 4, mujer)

Existe orgullo y felicidad por ser mapuche, lo cual se encuentra asociado a la historia de este pueblo:

No, yo creo que feliz, pu, también, como dije, es un motivo de orgullo, es como esa historia que se va construyendo, de ver todo lo que la gente ha luchado, conservar eso, uno dice "esto tiene que ser algo muy importante para luchar por ello". (Persona 2, hombre) 
La fuerza espiritual (newen), propia de la cosmovisión mapuche, genera fuertes sentimientos asociados a la trascendencia:

Ser más emocionales, yo creo, las emociones se viven mejor, muy diferentes, no sé, es tan frío una cosa así, uno lo siente más del corazón, como buen mapuche (...) sentir la fuerza de que uno es mapuche al final, de que, si es como eso, igual es como difícil de explicar (...) como una fuerza que siente en el corazón uno como mapuche, que como que se siente mejor, como que no piensa tanto en uno, sino en los demás, así, más preocupado más que nada, hay un tema más de hacer lazos más fuertes (...) se siente una hermandad cuando se junta, a pesar de no conocer a las personas, se siente que es como un lazo, sí, que hay hermandad y cosas así, no es algo así como que pasó, sí que es como, altiro saludar y ya sentirse bien, muy diferente (...) (Persona 4, hombre)

El desarrollo de la identidad puede asociarse a sentimientos negativos o de malestar emocional. Esto se relaciona, en particular, a la comprensión de que los mapuche no solo no apoyaron la conformación del Estado chileno, sino que permanecen en conflicto con este, aún hasta nuestros días.

Uy... significa, bueno, hoy, ahora es un motivo de orgullo y a la vez es una carga, no. $\mathrm{O}$ sea, a veces en el sentido negativo, en el sentido de la discriminación muchas veces de la sociedad en sí, pero carga también en el sentido que uno sabe que arrastra, una lucha, una lucha que se lleva hace tiempo y que, bueno, todavía se está dando. (Persona 9, hombre)

Ahora en la actualidad a mí me hace sentir orgullosísima ser mapuche, sabí, pero no siempre ha sido así, cuando dije denante, cuando pequeña puedo decir que me sentía triste, me avergonzaba, enojada, confundida, no... no entendía muchas cosas. El orgullo siempre está, pero acarrea otras emociones que, que uno lo sobrepasa, que tiene que ver con la lucha de pueblo, tiene que ver con nuestros hermanos, entonces, es ambas cosas, po, es orgullo, pero también es tristeza, es enojo. (Persona 4, mujer)

La identidad étnica se expresa de manera activa o pasiva, según sea el involucramiento del sujeto en su proceso de exploración y su participación, individual o colectivamente, en acciones de aprendizaje y/o reivindicación cultural. La identidad activa recibe mayor valoración que la pasiva, que es entendida como una identidad instrumental o estratégica, que solo se usa para conseguir beneficios individuales, sin buscar el beneficio colectivo:

Sí, bueno, si bien siempre me sentí mapuche, cuando era más chica, más joven, no tenía una participación como muy... no sé, por ejemplo, no hablaba nada de mapudungun, no participaba en espacios con gente mapuche, quizás porque no tuve la posibilidad o quizás también porque no la buscaba (...). (Persona 11, mujer)

El tema de que, ya, por ejemplo, la asociación mapuche, ya que después eso, ya también de primera siempre todo había que pensar sobre la cultura, todo eso, pero, a la vez, eso también se va muy... como por así decir, se pone muy... más parte como más político, ese tema, se van por esos temas al final. Y eso ya es con otros fines, como que no es lo mismo, se siente de que ya ser mapuche... el mapuche vendría siendo por conveniencia, más por temas políticos. (Persona 7, hombre)

La identidad activa contempla no solo procesos de reflexión personales e internos del sujeto, sino que además está unida a un fuerte componente ético motivacional, que dirige la conducta a acciones reivindicativas que comúnmente se llevan a cabo en relación con otros, ya sea educando y compartiendo saberes culturales o participando directamente en organizaciones culturales o de derechos humanos y ciudadanos:

Para mí ser mapuche igual tiene que ver con un proceso personal de... no sé, qué tiene muchas etapas y, bueno, dentro de esas etapas, estaba lo que yo mencionaba de entender que estamos en un proceso súper importante de revitalización, de recuperación y yo creo que eso es lo... no sé, lo pondría como eje de lo que es ser mapuche hoy. (Persona 11, mujer)

La valoración de la identidad activa se asocia a la reafirmación cultural, entendida como la confirmación de la pertenencia al pueblo Mapuche; se acompaña de intensos sentimientos de orgullo. Este proceso inicia un segundo despertar en la persona, que coincide con el ingreso a la educación superior y se relaciona con la responsabilidad moral individual del sujeto. Este nuevo proceso de búsqueda identitaria lleva a una nueva actualización del self.

Es como algo que... que me queda grande todavía, significa como mucho trabajo por delante, por aprender, por sentir, por... como mucho por hacer todavía, como por... como que me siento responsable un poco, como de visibilizar, de hacerme cargo de mis raíces, como eso. (Persona 4, mujer)

La segunda crisis de identidad étnica, que se inicia con el ingreso a la universidad, es resuelta usualmente mediante la retribución al grupo de pertenencia. Esta retribución se realiza a través de conocimientos técnicos o profesionales y/o el traspaso cultural a nuevas generaciones u otras personas que requieren apoyo en el proceso de búsqueda y exploración de su propia identidad.

La retribución técnica/profesional implica usar lo aprendido en la educación superior para ayudar a la comunidad: 
De hecho, yo decidí cambiarme de carrera y estudiar una carrera para ponerla al servicio de las comunidades, sí, yo creo que es una herramienta que uno tiene que también aprovecharse uno de esto pa... para poder para beneficiar a tu misma gente, sí (...) (Persona 1, mujer)

La retribución cultural se refiere a acciones destinadas a revitalizar la cultura mapuche, tales como su cosmovisión, la lengua y la alimentación:

De hacer cosas para el pueblo, de ayudar a otra gente que está en mi misma situación o que aún le falta ese paso para identificarse, siento que las personas mapuche tenemos una obligación de estar con nuestro pueblo y de hacer cosas para que todo mejore, entonces, hoy ser mapuche es ser un luchador o una luchadora. Hay muchas cosas por hacer. (Persona 4, mujer)

Finalmente, existiría una gama de valores compartidos por los jóvenes. Esta serie de valores asigna una evaluación muy positiva a la colectividad, que se manifiesta a través de aspectos prácticos culturales, cotidianos y domésticos que describen a la persona mapuche en su diario vivir. Algunos ejemplos de ellos son: la participación en ceremonias tradicionales, la alimentación o la disposición de la cama, entre otras referencias prácticas cotidianas.

En los próximos ejemplos se puede apreciar, una mirada colectiva/interrelacional de la vida, es decir, se vive en constante interacción y dependencia con otros, que forman parte del tejido social del sujeto:

Al final, uno se acoge con su gente, yo creo, por ejemplo, no sé, pu, cuando yo me siento mal acá, pienso en mi propia gente, pienso que igual lo estoy haciendo por ellos, pienso que estoy aprovechando oportunidades que a ellos no se les dieron. En ese sentido, igual yo creo que siempre ha sido una constante eso, refugiarse con su gente, hablarlo con gente que ha pasado por lo mismo, si al final uno solo tal vez pueda resistir, pero uno también es humano, en ese sentido, uno llega un punto en que uno se cansa y es ahí donde con su gente uno encuentra apoyo en realidad. Los mismos trabajos que uno puede avanzar solo hasta cierto punto, pero con su gente es donde uno lleva trabajo bien, pu, trabajo a largo plazo. Yo creo que es esa la técnica. (Persona 9, hombre)

Ahí fui conociendo gente que... amigos que son mapuche, como que ellos me fueron, de cierta forma, tirando, casi obligando a reconocerme como mapuche, que igual es bacán, como que no fue un proceso tan individual, creo que fue mucho más colectivo, fueron como ellos invitándome, ellos tensándome "¿Por qué no eres mapuche? ¿Por qué no? ¿Por qué? ¿Por qué?" hasta que en verdad me quedé sin respuestas. (Persona 16, mujer)

La importancia asignada a la colectividad se traduce en la participación de los y las jóvenes en agrupaciones culturales, donde se revitaliza la lengua y algunas costumbres, que enfatizan la cosmovisión tradicional. Se incluyen ritos y ceremonias ancestrales, como el nguillatún (ceremonia religiosa tradicional), wetripantu (ceremonia tradicional de año nuevo) o palín (deporte tradicional), la alimentación y un vínculo especial con la naturaleza, que puede o no incluir el contacto cotidiano con seres y/o fuerzas espirituales que cohabitan con los seres humanos:

Bueno, acá converso con las personas más cercanas, que viven casi similar a como yo vivo, también, compartir experiencias, conocimientos, hablar de la familia o a veces, incluso, molestarse así en chedungun, molestarnos, hablar, aunque a veces improperios, pero... [risas]. (Persona 14, mujer)

Sí, antes la acompañaba a los wetripantu, a las actividades que hacían relacionadas al ser mapuche, porque en esas actividades se enseñaba la comida, la lengua, todo eso, y ahí a veces la acompañaba y aprovechaba de aprender y de compartir con demás personas que son mapuche. (Persona 7, hombre)

No, yo esto lo asumí desde que era chico, porque siempre, no sé, hemos participado en nguillatún, palín (...) (Persona 8, hombre)

Y como siempre estuve ligada al territorio y oía hablar a gente contar sus historias sobre los kalku [brujo que se asocia con fuerzas negativas], no sé, tantas historias, historias que tienen que ver con el pueblo Mapuche, como se creó el mundo, por ejemplo, y conversar con mis compañeros que tenían otros conceptos de existencia y, no sé, la historia de los kalku eran mitos para ellos (...) (Persona 4, mujer)

Yo creo que la relación como con la identidad está dada, por una parte, dada por la relación con la naturaleza, pero también con uno mismo, como... como uno recibe las cosas, como te afectan también, como algo más espiritual, más externo con los demás y con el entorno. (Persona 1, mujer)

Por último, la relación cotidiana con la familia extensa está muy presente en el discurso de los y las jóvenes que participan de este estudio. Se pone especial énfasis en los antiguos, que incluye tanto a adultos mayores, como antepasados y ancestros que ya no están presentes. Todos ellos forman parte de los aspectos cotidianos que son considerados importantes para la conformación de la identidad mapuche:

Uy, no sé... [no logra entenderse claro, está llorando] cómo le cuento, yo crecí en ciudad, igual con cercanías, pero poco, y ahora que estoy más grande y decidida como de manera personal por... no sé qué cosa, igual, yo misma acercándome a mis abuelos, que aún los tengo vivos, preguntándole cosas, igual, no sé, igual, ellos ven como el 
entusiasmo, como que siento que ellos... como que a través de la mirada, igual como que me hablan, no sé, es una sensación muy rara, pero como que... como conversando hace poco, me pasó que mi abuela estaba contenta, siempre me intenta guiar y aconsejar. (Persona 15, mujer)

Desde niña tengo muy claro la persona que soy y lo que soy, de dónde vengo, mis antepasados... nuestra lengua, que igual se perdió mucho, por ejemplo, yo misma he escuchado desde mi bisabuela, mi abuela, mi mamá, ellas son hablantes, pero desde mi mamá ya empezó a hablar en castellano (...) (Persona 12, mujer)

\section{Discusión}

El principal hallazgo de nuestro estudio es la descripción de un proceso más o menos común, caracterizado por la presencia de dos despertares culturales, uno en la primera infancia y otro en la adolescencia, asociados a complejas tensiones identitarias relacionadas a los cuestionamientos del endogrupo y exogrupo sobre qué significa ser mapuche. Si bien Aravena Reyes (2003) ya había descrito la importancia del despertar cultural en el proceso de identificación cultural de personas mapuche, que se entiende como una toma de consciencia de pertenencia, nuestra investigación destaca el carácter dinámico de dicho proceso, asociado fuertemente a la escolarización de los y las participantes. El primer despertar cultural se produciría con el ingreso a la escuela, donde comienzan a gestarse tensiones identitarias que generan malestar emocional en los y las niñas. Estas tensiones se relacionan con los constantes cuestionamientos, tanto del exogrupo como del endogrupo, a partir de la presencia o ausencia de elementos culturales objetivos que se relacionan con la cultura tradicional rural. Este malestar, como veremos más adelante, se minimiza cuando se adopta la decisión de explorar la identidad mapuche de forma activa y permanente, a través del aprendizaje autorregulado de elementos culturales. Este último proceso, asociado al ingreso a la educación media y superior, daría cuenta de un segundo despertar cultural.

Tal como lo describe Tajfel (1981/1984), durante los primeros años de vida de nuestros participantes, los componentes cognitivos y afectivos, se incorporan principalmente desde la familia, a través de la socialización primaria. Estos se mantienen en armonía, es decir, no generan mayores cuestionamientos en la vida cotidiana. No obstante, nuestros participantes plantean que, con el ingreso a la educación formal primaria, aparecerían las primeras tensiones y/o cuestionamientos identitarios, asociados primariamente a la entrega de contenidos curriculares de la asignatura de historia de Chile, lo que posteriormente llevaría, por primera vez, a estos menores a reconocerse distintos a la identidad social dominante o chilena.

Según Toledo Jofré et al. (2015), la enseñanza de algunos contenidos de historia que pueden ser considerados conflictivos o controversiales, como la disminución de la población indígena producto de la llegada de los españoles o el terrorismo de Estado asociado a la dictadura militar, no pasarían desapercibidos para los profesores, en términos de sus propias posturas ideológicas y estilos de enseñanza. Los profesores utilizarían, entre otros, un estilo evitativo, objetivo o adoctrinador para impartir estos contenidos, lo que generaría sentimientos de malestar emocional en los alumnos. Este efecto negativo sería mayor en aquellos alumnos que están directamente relacionados con los contenidos revisados; en este caso, alumnos de grupos pertenecientes a minorías étnicas.

Así, al término de la primera infancia y comienzos de la segunda, se genera lo que Aravena Reyes (2008) denomina primer despertar cultural o la primera toma de consciencia de pertenencia a un determinado grupo. Esta coincide, además, con la crisis normativa del desarrollo de laboriosidad versus inferioridad (Erikson, 1968/1971), en la que la tarea fundamental de desarrollo del niño o niña consiste en resolver de manera adaptativa el sentido de competencia, generalmente motivados por la comparación con sus pares al ingresar a la educación prebásica o básica en nuestro país. Los hallazgos de nuestra investigación muestran que, como resolución de esta crisis normativa, los niños y niñas mapuche generan una primera sensación de incomodidad asociada a la idea de no tener claro si son parte del grupo "bueno" o "malo". Es desde esta incertidumbre que comienza a gestarse el proceso de conformación identitaria, el autoestima y autoconcepto de estos niños.

Con el ingreso a la escuela se activan, además, procesos de categorización social, es decir, componentes cognitivos y afectivos de la identidad, que se desencadenan a través de la interiorización de los valores (Vygotski, ca. 1928-1931/1996). De este modo, los jóvenes de nuestro estudio mencionan que han comenzado a descubrir que los sentimientos que imperan en "los otros" respecto de la cultura mapuche son principalmente negativos. Un ejemplo de esto es la sensación de enterarse por primera vez que forman parte del grupo que no solo apoyó a los españoles en la formación del Estado chileno, sino que además sigue "causando problemas" hasta hoy en día. De aquí se desprende la primera pregunta que los participantes 
buscan responder en torno a su identidad étnica: ¿es, entonces, bueno o malo ser mapuche? Junto con lo anterior, Merino et al. (2008) describen que aparecerían las primeras burlas o comentarios racistas, que surgen de aquellos que se consideran no mapuche.

Como ya hemos mencionado, frente al primer despertar cultural, a fines de la primera o comienzos de la segunda infancia, aparece el uso de estrategias identitarias individuales y colectivas, que apuntan a la resolución del conflicto interno (Tajfel, 1981/1984). Algunas de las que se encuentran presentes en nuestros participantes son la negación de la identidad o el uso de la creatividad social, a partir del diálogo con la familia extensa y la comunidad. En el primer caso, el o la menor resuelve no formar parte del grupo que es valorado negativamente. Para esto, hace uso de sus apellidos, si estos no son mapuche; de lo contrario, alude directamente al proceso de mestizaje. El segundo caso permite reinterpretar positivamente la procedencia cultural, destacando los aspectos comparativos positivos que componen su cultura y que no están presentes en el exogrupo dominante. Mientras el uso de esta última estrategia se traducirá, a largo plazo, en reafirmación cultural, la negación de la identidad, por el contrario, será percibida como una mancha en la honra, que acompañará con vergüenza al o la joven a lo largo de la vida, generando la percepción subjetiva de daño permanente, sensación de debilidad o falta de dignidad. Todos son sentimientos negativos que son descritos por las personas entrevistadas y que van a impactar su desarrollo humano.

Phinney (1990) plantea que durante la adolescencia se acentúa el proceso de exploración y búsqueda de información de la identidad en los jóvenes. Como etapa del desarrollo, la adolescencia tiene también una tarea principal: resolver la crisis de identidad, que exige integrar varias visiones de sí mismo en el autoconcepto y la autoestima (Erikson, 1968/1971). El cuestionamiento identitario permanente, que se describe como hallazgo en nuestros resultados, tensiona los componentes cognitivos y afectivos de los niños, niñas y adolescentes mapuche. La valencia positiva o negativa que surge como resultado de la tensión identitaria en la niñez genera la necesidad de explorar y aprender los elementos culturales en la adolescencia. Esto es coincidente con la literatura citada en nuestra investigación y también con lo que llamamos segundo despertar cultural.

El proceso de reinterpretación cultural en los jóvenes mapuche se inicia con un aprendizaje dirigido por ellos/as mismos/as, que busca resolver la disonancia que genera la tensión identitaria. Este tipo de aprendizaje presenta características de aprendizaje autorregulado (Zimmerman, 2001). Este proceso requiere necesariamente lo que Aravena Reyes (2008) llama consciencia de pertenencia. Lo cultural se circunscribe, entonces, a lo colectivo, que, a su vez, está situado histórica y geográficamente (Martín-Baró, 1989). Es en este contexto que comienza a gestarse un segundo proceso de identificación cultural, que tendrá como resultado la autoadscripción de estos jóvenes mapuche. Este segundo despertar cultural coincide con el fin de la adolescencia y el ingreso a la educación superior.

El proceso de exploración permanente de la identidad étnica conlleva, entonces, un aprendizaje distinto al de otras identidades. Los jóvenes buscan información de la cultura de origen, con el objetivo de incorporar y/o perfeccionar elementos culturales que aumentarán la valoración positiva de la identidad. Este proceso es dinámico y se ubica en el interfaz de lo individual y lo colectivo. Los jóvenes pueden reaprender de manera individual algunos elementos de su cultura. Sin embargo, la valoración positiva se adquiere conforme se es activo en este proceso y, para esto, necesariamente se debe buscar a otros que comparten este saber o kimün con ellos (Merino et al., 2017). Se debe, entonces, tener en cuenta procesos tanto cognitivos como afectivos, componentes objetivos y subjetivos, para entender la complejidad de la conformación identitaria en estos jóvenes a lo largo de sus vidas.

Los discursos de los participantes de nuestra investigación muestran que la expresión activa de la identidad mapuche tiene su origen en la percepción subjetiva de que se tiene una responsabilidad moral y ética, en la que el peso de la retribución cultural cobra fuerza. Desde este punto de vista, la estructura más colectivista del pueblo Mapuche valora la conversación que comparte saberes, el nütram, es decir, la acumulación de conocimientos (información) en un individuo no es un elemento considerado útil ni valioso por los jóvenes si no es al alero del compartir con otros, ya sea para enseñar o aprender más. La contribución social, el aporte que hace cada individuo dentro de su cultura, es valorada positivamente por los y las participantes. No resulta ilógico pensar, entonces, que este tipo de actividades que refuerzan la expresión activa de la identidad tengan un impacto positivo también en el bienestar social y subjetivo de estos jóvenes (Keyes, 1998).

Finalmente, para las personas jóvenes que participaron en nuestra investigación resulta muy positivo responder a la necesidad de retribución hacia su cultura. La revitalización de elementos culturales, como la 
lengua o la asistencia a ceremonias tradicionales, es acompañada por sentimientos de bienestar, que son percibidos como parte de esta conformación permanente de la identidad y están fuertemente ligados al reconocimiento social y al aporte que pueden hacer en tanto sujetos individuales y colectivos.

La principal limitación de nuestro estudio es que, si bien presentamos las tensiones identitarias con respecto a la identidad étnica y el malestar que ellas provocan, no ahondamos en otras identidades que podrían influir en la tensión y su resolución. Por ejemplo, resultaría interesante estudiar cómo puede afectar el género y las diferencias territoriales en este proceso. Adicionalmente, otra limitación es que la muestra fue por conveniencia, lo que impide generalizar los resultados a otros jóvenes mapuche.

Entre las proyecciones posibles de este estudio, estaría determinar la magnitud del daño causado en las personas, a propósito de los sentimientos de malestar asociados a la vivencia de discriminación étnica o a la presencia de continuas tensiones identitarias y/o procesos permanentes de validación de la identificación cultural. Por otra parte, la literatura menciona que la identidad étnica podría funcionar como factor protector ante este tipo de episodios de discriminación, ya que esta fortalece la autoestima y el autoconcepto del sujeto. Realizar un estudio cuantitativo, estableciendo perfiles de personas mapuche a partir de grados de identificación étnica, permitiría evaluar la existencia de diversos grados de identificación, según aspectos cognitivo-conductuales, afectivos y culturales. Esto nos posibilitaría poner a prueba un modelo teórico que incluya las variables de identidad y discriminación étnica, además del efecto en los procesos afectivos y/o el bienestar en jóvenes mapuche.

Cualitativamente, se podría aumentar la profundidad de la investigación, a través de un estudio narrativo biográfico o a partir de entrevistas de historia de vida. En particular, resulta de interés estudiar el ingreso a la educación formal y la exposición a los contenidos de historia relativos a la historia mapuche. Realizar un proceso de inmersión en la identidad mapuche desde la etnografía podría aportar cualitativamente aspectos mucho más específicos a la investigación acerca del desarrollo de la identidad mapuche.

\section{Conclusiones}

Según las teorías clásicas del desarrollo evolutivo, es esperable que los jóvenes enfrenten y resuelvan crisis identitarias. Los jóvenes mapuche urbanos no escapan a esto; sin embargo, sienten, además, la necesidad de rescatar aspectos culturales que se han perdido a lo largo de la historia. Mientras conviven con la responsabilidad moral de revitalizar estos elementos culturales, que se saben en riesgo de pérdida por aculturación, son, a la vez, juzgados y medidos por no poseerlos desde el origen de su vida, tanto por el endogrupo o grupo de pertenencia como por el exogrupo o grupo dominante, en este caso, la sociedad no mapuche.

La resolución de la crisis identitaria se ve dificultada por esta interpelación constante a su identificación con el pueblo Mapuche, tanto por la ausencia de elementos culturales tradicionales como por su residencia en zonas urbanas. Este cuestionamiento, realizado tanto por el endogrupo como por el exogrupo, se traduce en una sola afirmación: tú no eres tan mapuche. ¿Qué debo hacer? o ¿cómo se supone que debo ser? se preguntan, entonces, los y las jóvenes en la permanente tensión cotidiana en que se mueven.

Este cuestionamiento interno coincide con lo planteado en la literatura, pues los procesos de negociación de la identidad mapuche cobran actualmente gran importancia a propósito del contexto de globalización en el que los jóvenes se encuentran insertos. La persona joven es quien más expuesta está ante las tensiones identitarias. Por lo mismo, es relevante comprender cómo se construye esta identidad en estos jóvenes en particular. Es decir, cómo se va consolidando el proceso de identificación cultural a la luz de este constante cuestionamiento y de las vivencias discriminatorias que describen haber sufrido a lo largo de sus vidas.

No sabemos con exactitud el impacto que este escenario de constante validación social tiene en la salud mental y física de estas personas, pero sí sabemos que impacta su bienestar subjetivo y social, a través de sentimientos de malestar asociados tanto a esta constante tensión como a la discriminación étnica. Esto es razón suficiente para sospechar que se estarían dañando estructuras psicológicas importantes, como el autoconcepto y la autoestima de estas personas. Por ende, estaríamos frente a un sector de nuestra población que no solo ve mermado su bienestar a lo largo de la vida, lo que ya vulnera su desarrollo humano, en tanto se le niega la posibilidad de estar satisfecho con la vida, sino que también podrían presentar mayores factores de riesgo de padecer trastornos del ánimo, como depresiones o actos de suicidio. 


\section{Referencias}

Alfaro, S. (2007). Ser indígena es algo relativo: construcción de identidades étnicas y acciones afirmativas en Perú y Chile. En J. Ansion \& F. Tubino (Eds.), Educar en ciudadanía intercultural: experiencias y retos en la formación de estudiantes universitarios indigenas. (pp. 111-140). Fondo Editorial.

Aravena, A. \& Baeza, M. A. (2017). Imaginarios sociales y construcción intersubjetiva de alteridad. La prensa escrita y la cuestión mapuche en Chile. Cultura y Representaciones Sociales, 12(23), 7-29. http://www.scielo.org.mx/pdf/crs/v12n23/2007-8110-crs-12-23-00007.pdf

Aravena Reyes, A. (2003). La identidad mapuche-warriache: procesos migratorios contemporáneos e identidad mapuche urbana. América Indigena, 59(4), 162-188. https://www.researchgate.net/publication/266062194_Los_mapucheswarriaches_procesos_migratorios_contemporaneos_e_identidad_mapuche_urbana

Aravena Reyes, A. (2008). Mapuches en Santiago memorias de inmigrantes y residentes: relatos para una antropología implicada sobre indigenas urbanos. Escaparate.

Baeza, M. A. (2002). De las metodologías cualitativas en investigación científico social: diseño y uso de instrumentos en la producción de sentido. Universidad de Concepción.

Canales Cerón, M. (Ed.). (2006). Metodologías de investigación social: introducción a los oficios. LOM.

Cayuqueo, P. (2012). Solo por ser indios y otras crónicas mapuches. Catalonia.

Diener, E. (2000). Subjective well-being: The science of happiness and a proposal for a national index. American Psychologist, 55(1), 34-43. https://doi.org/10.1037/0003-066x.55.1.34

Erikson, E. H. (1971). Identidad, juventud y crisis (M. Galeano, Trad.). Paidós. (Obra original publicada en 1968)

Espinosa Pezzia, A. \& Tapia, G. (2011). Identidad nacional como fuente de bienestar subjetivo y social. Boletín de Psicología, $102,71-87$. https://investigacion.pucp.edu.pe/grupos/gpp/wp-content/uploads/sites/102/2014/09/Espinosa-y-Tapia-2011.pdf

Genna, K. \& Espinosa, A. (2012). Identidad, etnicidad y bienestar social en un contexto socialmente excluyente. Psicologia \& Sociedade, 24(1), 84-93. https://doi.org/10.1590/S0102-71822012000100010

Instituto Nacional de Estadísticas. (2018). 2a entrega resultados definitivos Censo 2017 [Conjunto de datos]. https://www.censo2017.cl/wpcontent/uploads/2018/05/presentacion_de_la_segunda_entrega_de_resultados_censo2017.pdf

Jiménez Bustos, R. A., Pérez-Luco Arenas, R. J. \& Bustamante Rivera, G. E. (2017). Identidad étnica y conductas sociales en adolescentes indígenas mapuche sancionados por la ley de responsabilidad penal adolescente en regiones del sur de Chile. Universitas Psychologica, 16(1), 1-22. https://doi.org/10.11144/Javeriana.upsy16-1.iecs

Keyes, C. L. M. (1998). Social well-being. Social Psychology Quarterly, 61(2), 121-140. https://doi.org/10.2307/2787065

Krause, M. (1995). La investigación cualitativa: un campo de posibilidades y desafíos. Revista Temas de Educación, 7, 19-39. https://www.researchgate.net/publication/215561167_La investigacion_cualitativa_Un campo_de_posibilidades_y_desafios

Martín-Baró, I. (1989). Sistema, grupo y poder: psicología social desde Centro América.UCA Editores.

Merino, M. E., Becerra, S. \& De Fina, A. (2017). Narrative discourse in the construction of Mapuche ethnic identity in context of displacement. Discourse \& Society, 28(1), 60-80. https://doi.org/10.1177/0957926516676695

Merino, M. E., Quilaqueo, D. \& Saiz, J. L. (2008). Una tipología del discurso de discriminación percibida en mapuches de Chile. Revista Signos, 41(67), 279-297. https://doi.org/10.4067/S0718-09342008000200011

Merino, M. E. \& Tileagă, C. (2011). La construcción de identidad de minorías étnicas: un enfoque discursivo psicológico a la autodefinición étnica en acción. Discurso \& Sociedad, 5(3), 569-594. http://www.dissoc.org/ediciones/v05n03/DS5\%283\%29Merino\&Tileaga.pdf

Merino, M. E. \& Tocornal, X. (2012). Posicionamientos discursivos en la construcción de identidad étnica en adolescentes mapuches de Temuco y Santiago. Revista Signos, 45(79), 154-175. https://doi.org/10.4067/S0718-09342012000200003

Ministerio de Desarrollo Social. (2015). CASEN 2013. Pueblos indígenas: sintesis de resultados. Gobierno de Chile. https://ewsdata.rightsindevelopment.org/files/documents/05/IADB-CH-L1105_Tkl0PB3.pdf

Oteíza, T. \& Merino, M. E. (2012). Am I a genuine Mapuche? Tensions and contradictions in the construction of ethnic identity in Mapuche adolescents from Temuco and Santiago. Discourse \& Society, 23(3), 297-317. https://doi.org/10.1177/0957926511433455

Pavot, W. \& Diener, E. (2008). The Satisfaction With Life Scale and the emerging construct of life satisfaction. The Journal of Positive Psychology, 3(2), 137-152. https://doi.org/10.1080/17439760701756946

Pérez-Luco Arenas, R., Lagos Gutiérrez, L., Mardones Barrera, R. \& Sáez Ardura, F. (2018). Taxonomía de diseños y muestreo en investigación cualitativa. Un intento de síntesis entre las aproximaciones teórica y emergente. Ámbitos: Revista Internacional de Comunicación, 39, Artículo 11. https://institucionales.us.es/ambitos/taxonomia-disenos-muestreo-investigacion-cualitativa-intentosintesis-las-aproximaciones-teorica-emergente/

Pérez Ruiz, M. L. (2011). Retos para la investigación de los jóvenes indígenas. Alteridades, 42, 65-75. http://www.scielo.org.mx/scielo.php?pid=S018870172011000200005\&script=sci_abstract\&tlng=pt

Peris Pichastor, R. \& Agut Nieto, S. (2007). Evolución conceptual de la identidad social. El retorno de los procesos emocionales. R.E.M.E. (Revista Electrónica de Motivación y Emoción), 10(26-27), Artículo 1. http://reme.uji.es/articulos/numero26/article2/article2.pdf

Phinney, J. S. (1990). Ethnic identity in adolescents and adults: Review of research. Psychological Bulletin, $108(3)$, $499-514$. https://doi.org/10.1037/0033-2909.108.3.499

Phinney, J. S. \& Ong, A. D. (2007). Conceptualization and measurement of ethnic identity: Current status and future directions. Journal of Counseling Psychology, 54(3), 271-281. https://doi.org/10.1037/0022-0167.54.3.271

QSR International. (2015). NVivo qualitative data analysis software (Versión 11) [Software computacional]. https://www.qsrinternational.com/nvivoqualitative-data-analysis-software/support-services/nvivo-downloads

Sarmiento, A. V., Pérez, M. V., Bustos, C., Hidalgo, J. P. \& Vergara del Solar, J. I. (2019). Inclusion profile of theoretical frameworks on the study of sociocultural adaptation of international university students. International Journal of Intercultural Relations, 70, 1941. https://doi.org/10.1016/j.ijintrel.2019.02.004

Tajfel, H. (1984). Grupos humanos y categorías sociales: estudios de psicología social (C. Huici, Trad.). Helder. (Obra original publicada en 1981)

Toledo Jofré, M. I., Magendzo Kolstrein, A., Gutiérrez Gianella, V. \& Iglesias Segura, R. (2015). Enseñanza de 'temas controversiales' en la asignatura de historia y ciencias sociales desde la perspectiva de los profesores. Estudios Pedagógicos, 41(1), 275-292. https://doi.org/10.4067/s0718-07052015000100016

Verkuyten, M. \& de Wolf, A. (2002). Being, feeling and doing: Discourses and ethnic self-definitions among minority group members. Culture \& Psychology, 8(4), 371-399. https://doi.org/10.1177/1354067X0284001 
Vygotski, L. S. (1996). Obras escogidas IV: psicología infantil (J. G. Blanc, Trad.). Aprendizaje Visor. (Obras originales publicadas ca. 1928-1931)

Zañartu Canihuante, N., Aravena Reyes, A., Grandón Fernández, P., Sáez Delgado, F. \& Zañartu Canihuante, C. (2017). Identidad étnica, discriminacion percibida y procesos afectivos en jóvenes mapuches urbanos. CUHSO: Cultura-Hombre-Sociedad, 27(2), 229250. https://doi.org/10.7770/cuhso-V27n2-art1226

Zimmerman, B. J. (2001). Theories of self-regulated learning and academic achievement: An overview and analysis. En B. J. Zimmerman \& D. H. Schunk (Eds.), Self-regulated learning and academic achievement: Theoretical perspectives (2a ed., pp. 1-38). Lawrence Erlbaum.

\section{Anexo}

\section{Pauta de Entrevista}

Para la construcción de esta pauta, se usó como referencia parte de la pauta utilizada en el proyecto FONDECYT de iniciación $\mathrm{N}^{\mathrm{o}} 11130384$ "Imaginarios sociales de la identidad mapuche en El Gran Concepción", de la investigadora Dra. Andrea Aravena Reyes.

\section{Autoadscripción}

- ¿Se considera usted mapuche? ¿por qué?

- ¿Cuán importante es para usted ser mapuche? ¿por qué?

\section{Dinámica}

- ¿Siempre se ha considerado mapuche? (Se distinguen aspectos propios de la infancia, adolescencia y momento actual).

\section{Expresión de la identidad}

- ¿Qué significa para usted ser mapuche hoy? ¿en la ciudad?

- ¿Cómo se vive el ser mapuche?

\section{Sentimientos}

- ¿Cómo se siente usted por ser mapuche? ¿por qué?

\section{Valores compartidos}

- ¿Cuáles son los aspectos prácticos del día a día que reflejan ser mapuche?

Fecha de recepción: Octubre de 2018.

Fecha de aceptación: Abril de 2020. 